\title{
Political and social determinants of life expectancy in less developed countries: a longitudinal study
}

\author{
Ro-Ting Lin ${ }^{1 \dagger}$, Ya-Mei Chen ${ }^{1 \dagger}$, Lung-Chang Chien² and Chang-Chuan Chan ${ }^{1,3^{*+}}$
}

\begin{abstract}
Background: This study aimed to examine the longitudinal contributions of four political and socioeconomic factors to the increase in life expectancy in less developed countries (LDCs) between 1970 and 2004.

Methods: We collected 35 years of annual data for 119 LDCs on life expectancy at birth and on four key socioeconomic indicators: economy, measured by log10 gross domestic product per capita at purchasing power parity; educational environment, measured by the literacy rate of the adult population aged 15 years and over; nutritional status, measured by the proportion of undernourished people in the population; and political regime, measured by the regime score from the Polity IV database. Using linear mixed models, we analyzed the longitudinal effects of these multiple factors on life expectancy at birth with a lag of 0-10 years, adjusting for both time and regional correlations.
\end{abstract}

Results: The LDCs' increases in life expectancy over time were associated with all four factors. Political regime had the least influence on increased life expectancy to begin with, but became significant starting in the 3rd year and continued to increase, while the impact of the other socioeconomic factors began strong but continually decreased over time. The combined effects of these four socioeconomic and political determinants contributed $54.74 \%-98.16 \%$ of the life expectancy gains throughout the lag periods of 0-10 years.

Conclusions: Though the effect of democratic politics on increasing life expectancy was relatively small in the short term when compared to the effects of the other socioeconomic factors, the long-term impact of democracy should not be underestimated.

Keywords: Life expectancy, Socioeconomic factors, Developing countries, World health, Political factors, Public health, Malnutrition, Literacy, Democracy

\section{Background}

The extension of life expectancy has always been a primary interest of medical research as well as an indicator of national public health profiles [1]. Life expectancy has exhibited patterns of continuous growth over time, but it has also demonstrated persistently high variability between countries over the past half-century $[2,3]$. As of 2008, the gap in life expectancy between regions

\footnotetext{
* Correspondence: ccchan@ntu.edu.tw

+ Contributed equally

${ }^{1}$ Institute of Occupational Medicine and Industrial Hygiene, College of Public Health, National Taiwan University, Room 722, No. 17, Xuzhou Road, Taipei

City 100, Taiwan

Full list of author information is available at the end of the article
}

classified by the United Nations (UN) as more developed and less developed was as high as 11 years [4].

Changes in life expectancy can result from long-term changes in many factors, including political regime and socioeconomic status $[5,6]$. Political regime has been used as a distal determinant of life expectancy at the country level $[7,8]$. A more democratic country may more readily recognize citizens' rights to voice and act on political opinions, and therefore may produce public services that are more closely tied to social needs $[9,10]$. Under electoral incentives, politicians govern public policies on labor market and welfare issues to avoid famine, to increase per capita income, to increase public health and medical care expenditures, and to improve 
the health and quality of life of the population $[8,10]$. For example, labor market policies that promote higher employment rates and salary levels could contribute to better economic status and population health [8]. Furthermore, investment in welfare and health policiessuch as ensuring safe childbirth for mothers and babies, securing children's right to nutrition, enhancing education of women and children, and increasing accessibility of public health and medical services-could benefit population health by redistributing resources to more people who are in need $[8,11,12]$.

There has been growing interest in the concept of political empowerment and related health outcomes [13-15]. Powerlessness, or the lack of control over one's destiny, may be a broad-based risk factor for disease. Empowerment can be demonstrated to be an important promoter of health [16]. Some studies have shown that people who live in more democratic societies, which were assumed to empower people with more autonomy, have longer life expectancies and lower mortality rates than do people who live in more autocratic societies; other studies have shown that democracy has little or no effect on mortality rates among the poor $[7,8,17]$. For example, South Africa became a representative democracy in 1994, but it has shown worsening health indicators ever since [18]. Reviews of the influence of democracy on population health over time have not only been intriguing [10], but have hypothesized and proven that democracy has real and important effects on the daily lives and well-being of individuals around the globe $[8,10]$.

However, the influence of political regime and socioeconomic factors on life expectancy has yet to be studied comprehensively, and analysis of the long-term effects of political regime is particularly lacking. By nature, a time lag exists between policy design and the full effect of the policy $[17,19]$. Even if a changing political regime initiates immediate changes to public services, the level of public services produced by the state will take time to change significantly. The lack of comprehensive studies has been mainly due to the limitations of short study time frames and the scarcity of comparable data [7]. These limitations may have contributed to the inconsistent research findings regarding democracy and life expectancy. Study design could be another factor contributing to the inconsistent findings. Previous studies investigating social and policy determinants' long-term effects on health outcomes on a global scale used regression analyses and data from a single time point to predict health outcomes at a single time point [10]. Such design is subject to the influence of global socioeconomic changes: the findings may vary depending on the socioeconomic changes in the world during that specific period of time $[7,8,10]$.
Moreover, regression techniques may ignore withincountry correlations when longitudinal data are modelled, and thus lead to biased estimates of regression parameters and results [20]. Other designs, such as time series analyses, may drive a better estimation of the association between time-varying determinants and the longitudinal trend of life expectancy. For this study, publicly available country-specific long-term data on life expectancy and political and socioeconomic factors enabled us to address these important issues through longitudinal data modelling.

This study aimed to investigate the longitudinal relationships between life expectancy and national developments in political regime in less developed countries (LDCs). Life expectancy at birth was the outcome variable. Life expectancy at birth reflects the overall mortality rate of a population with consideration of infant and child mortality, which are susceptible to both political and socioeconomic risk factors $[7,8]$. The inclusion of child health is also important because it can reflect public health policies and efforts against infectious diseases and malnutrition $[8,21]$.

In addition to political regime, several main socioeconomic indicators found to be important determinants of life expectancy, such as economy, educational environment, and nutritional status, were also included for investigation [22-24]. Variations in life expectancy across countries have been attributed, in cross-sectional studies, to increases in national income (by $10 \%-25 \%$ ) and literacy (by 59\% - 64\%), after controlling for the state of the economy and the level of income inequality [23,24]. Poor nutritional status affects mothers and children in countries with low incomes and accounts for $11 \%$ of the global disease burden [21,25-27].

Unlike the studies which examined data from only one time point to predict health effects in the future, we examined the lagged effects of the selected factors on life expectancy at birth across a period of 35 years from 1970 to 2004. We adjusted for time and regional correlations in order to determine whether and how changes in life expectancy are the result of changes in the selected socioeconomic factors over time. To address these issues, we first present the longitudinal relationships between life expectancy in LDCs and the respective socioeconomic factors, and then illustrate the modelling results and estimations regarding the impact of each factor on life expectancy in LDCs between 1970 and 2004. Understanding from a longitudinal perspective how political regime and these multidimensional socioeconomic factors contribute to increased life expectancy could provide further evidence to support global health efforts, especially for developing countries $[28,29]$. 


\section{Methods}

We applied two classifications in selecting countries to be included as LDCs in this study. First, we used the classification employed by the United Nations (UN). We identified as LDCs 169 countries from regions classified by the $\mathrm{UN}$ as less developed, including Africa $(\mathrm{N}=57)$, Asia (with the exception of Japan) $(\mathrm{N}=42)$, Latin America and the Caribbean $(\mathrm{N}=48)$, and Oceania (with the exception of Australia and New Zealand) $(\mathrm{N}=22)$. Second, we followed the criteria for the "Developed World" category defined by the United States Census Bureau (USCB). We classified as LDCs those countries not included in the USCB's "Developed World" category [30]. Therefore, 20 Eastern and Southern European countries (with the exception of Italy) and 15 newly independent countries from the former Union of Soviet Socialist Republics were also identified as LDCs for this study. Out of these 204 total LDCs, 119 countries, representing $83.28 \%$ of the world's population from 2000-2004, had at least 1 year's worth of data available for analysis. These 119 countries with available data were included for analysis and are listed in Table 1.

\section{Data and measures}

We obtained data for each of the 119 LDCs on historical life expectancy at birth and on indicators of socioeconomic and political status over a 35-year period, 1970-2004, all from publicly available databases. The year-by-year life expectancy of each nation was based on interpolated demographic indicators included in information from the UN World Population Prospects and the United States Census Bureau (USCB) $[4,31]$.

The study investigated the following factors as determinants of life expectancy: economy, literacy, undernourishment, and political regime. Political regime was measured by a score that reflected the extent of democratic and autocratic authority patterns institutionalized in the country during its political lifespan [32]. The score used to measure the characteristics of a country's political regime was the POLITY2 variable from the Polity IV dataset. Polity IV was a project to measure longitudinal patterns of political characteristics and contestability for states in the world system [32]. In order to facilitate the use of the regime measure in time-series analyses, the Polity IV project modified a previously

Table 1 Countries included in the analysis, by geographical region ${ }^{a}(N=119)$

\begin{tabular}{|c|c|c|}
\hline Regions & $\mathrm{N}$ & Countries \\
\hline Africa & 45 & \\
\hline Eastern Africa & 15 & $\begin{array}{l}\text { Burundi, Comoros, Djibouti, Eritrea, Ethiopia, Kenya, Madagascar, Malawi, Mauritius, Mozambique, Rwanda, Tanzania, } \\
\text { Uganda, Zambia, and Zimbabwe }\end{array}$ \\
\hline Middle Africa & 6 & Cameroon, Central African Republic, Chad, Congo, Democratic Republic of the Congo, and Gabon \\
\hline Northern Africa & 5 & Algeria, Egypt, Morocco, Sudan, and Tunisia \\
\hline Southern Africa & 5 & Botswana, Lesotho, Namibia, South Africa, and Swaziland \\
\hline Western Africa & 14 & $\begin{array}{l}\text { Benin, Burkina Faso, Côte d'Ivoire, Gambia, Ghana, Guinea, Guinea-Bissau, Liberia, Mali, Mauritania, Niger, Nigeria, } \\
\text { Senegal, and Togo }\end{array}$ \\
\hline Oceania & 1 & Fiji \\
\hline Asia & 26 & \\
\hline Eastern Asia & 3 & China, Mongolia, and Republic of Korea \\
\hline Southern Asia & 6 & Bangladesh, India, Iran, Nepal, Pakistan, and Sri Lanka \\
\hline South-Eastern Asia & 7 & Cambodia, Indonesia, Laos, Malaysia, the Philippines, Thailand, and Vietnam \\
\hline Western Asia & 10 & Cyprus, Israel, Jordan, Kuwait, Lebanon, Saudi Arabia, Syria, Turkey, United Arab Emirates, and Yemen \\
\hline $\begin{array}{l}\text { Latin America and the } \\
\text { Caribbean }\end{array}$ & 23 & \\
\hline Caribbean & 5 & Cuba, Dominican Republic, Haiti, Jamaica, and Trinidad and Tobago \\
\hline Central America & 7 & Costa Rica, El Salvador, Guatemala, Honduras, Mexico, Nicaragua, and Panama \\
\hline South America & 11 & Argentina, Bolivia, Brazil, Chile, Colombia, Ecuador, Guyana, Paraguay, Peru, Uruguay, and Venezuela \\
\hline $\begin{array}{l}\text { Southern and Eastern } \\
\text { Europe }\end{array}$ & 12 & \\
\hline Eastern Europe & 4 & Bulgaria, Hungary, Poland, and Romania \\
\hline Southern Europe & 8 & Albania, Croatia, Greece, Macedonia, Portugal, Serbia and Montenegro, Slovenia, and Spain \\
\hline Eurasia & 12 & $\begin{array}{l}\text { Armenia, Belarus, Estonia, Kazakhstan, Latvia, Lithuania, Moldova, Russia, Tajikistan, Turkmenistan, Ukraine, and } \\
\text { Uzbekistan }\end{array}$ \\
\hline
\end{tabular}

$\mathrm{N}=$ number of countries. ${ }^{\mathrm{a}}$ Based on the United Nations' geographical regions 
categorical score into continuous score-the POLITY2 score [32]. The variable was transferred as a continuous variable either by scoring anarchy as zero or by prorating the score over the transition span for countries experiencing authority change [32]. The POLITY2 variable took into account and was weighted based on dimensions of openness and competitiveness in recruitment of political actors as well as on constraints on chief political executives [32]. The regime status was then scored on a spectrum ranging from -10 (strongly autocratic) to +10 (strongly democratic) [32]. The POLITY2 score was treated as a continuous variable for analysis in this and previous studies [9,32].

The measure used to indicate the state of each country's economy was calculated from the level of per capita income based on the yearly per capita gross domestic product (GDP) at purchasing power parity, in current prices. These data were extracted from the Penn World Table [33]. Literacy, measured as the proportion of the country's population over the age of 15 years who were literate, was used as a measure for educational environment. Literacy data were retrieved primarily from $\mathrm{UN}$ agencies $[34,35]$. Undernourishment was used as a proxy for nutritional status and was measured by calculating the proportion of each country's population whose dietary condition was continuously below a minimum dietary energy requirement. These data were extracted from UN Food and Agriculture Organization statistics [36]. For the purposes of our calculations, countries in which less than $2.5 \%$ of the population was undernourished had the relevant metric set to $2.5 \%$ [36].

\section{Statistical methods}

This study used the general linear mixed model to investigate the lagged effects of the political regime and socioeconomic factors on life expectancy while controlling both for autoregressive correlations over time and for regional correlations. We performed a PROC MIXED procedure using the SAS V9.1.3 software package (SAS Institute Inc., Cary, NC, USA) to analyze the longitudinal effects of the selected factors on life expectancy from 1970 to 2004. The life expectancy (Y) of a country was the dependent variable. Five fixed effectstime $(\mathrm{T})$, the common logarithm of the economy $(\mathrm{E})$, the literacy rate $(\mathrm{L})$, the proportion of the population undernourished $(\mathrm{U})$, and the political regime score $(\mathrm{P})-$ were taken as the independent variables. We applied linear mixed models [37-39] in which regional heterogeneous covariance were considered, as follows:

$$
Y i(k), j=b 0 i(k)+\beta 0+\beta 1 \times T i(k), j-t+\beta 2 \times \log 10 E i(k),
$$
$j-t+\beta 3 \times \operatorname{Li}(k), j-t+\beta 4 \times(100-U i(k), j-t)+\beta 5 \times P i(k), j-t$ $+b 1 \times \operatorname{Ti}(k), j-t+b 2 \times \log 10 E i(k), j-t+b 3 \times L i(k), j-t+$ $b 4 \times(100-U i(k), j-t)+b 5 \times P i(k), j-t+\varepsilon i(k), j-t$. where i denotes the country from $i=1$ to $i=119 ; \mathrm{k}$ denotes the country from the $k$ th geographic region (i.e., 16 regions based on the United Nations' classification of regions presented in Table 1); $j$ is the calendar year from 1970 to 2004; $t$ is the number of lag years from 0 to $10 ; b 0 i(k)$ denotes the random-effect parameter (i.e., the random intercept that estimates separate intercept values for each country); $\beta 0 \sim 5$ denotes the fixed-effects parameters; $b 0 \sim 5$ denotes the randomeffects parameters; and $\varepsilon i(k), j-t$ is the error term. In each case, the value of the time variable $\mathrm{T}$ was the difference between the calendar year and $1970+t$, since 1970 was regarded as the base year.

These linear mixed models were fitted with first-order autoregressive covariance structure matrices on the basis of Akaike's information criterion, and parameters were derived using maximum likelihood estimations. The parameter estimates of the first order autocorrelation coefficient ranged between 0.920 and 0.983 , indicating a highly autoregressive correlation among the different time points of the dependent variable. Parameter estimates in the models were used to calculate the gains in life expectancy attributable to the selected socioeconomic factors. A $p$ value of less than 0.05 was considered statistically significant in this study. Graphs were drawn using SigmaPlot V10.0 (Systat Software Inc., Richmond, CA, USA).

\section{Results}

All of the factors included in the current study contributed to prolonging life expectancy, but at different

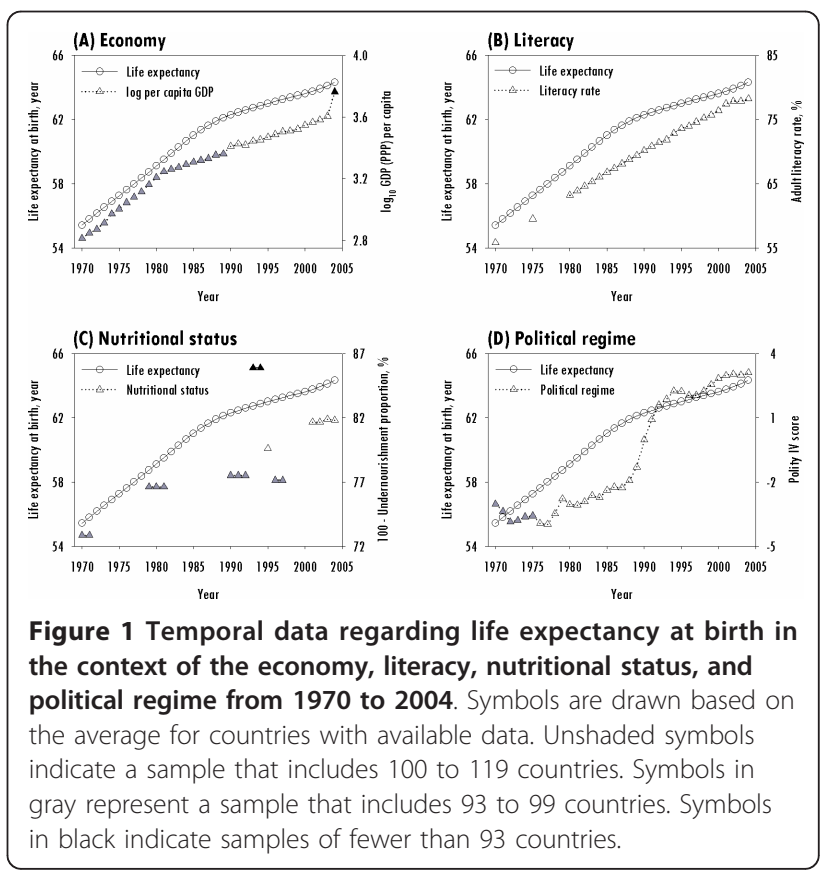


magnitudes. The influence of each factor on life expectancy changed over time. Figure 1 illustrates the temporal sequences of life expectancy at birth from 1970 to 2004 in the 119 LDCs included in the study and in the context of economy, educational environment (literacy), nutritional status (undernourishment), and political regime. Panel (A) shows that life expectancy increased by 8.9 years over the 35 years. During this time period, the log per capita GDP also increased, from 2.8 in 1970 to 3.6 in 2003. Economic growth was faster before 1980 than after. Panel (B) shows a steady increase in literacy rates, with an overall increase of $22.4 \%$, but we note that data were sparse in the 1970s. Panel (C) shows periodic data on nutritional status, with an overall decrease in undernourishment of $8.9 \%$. Panel (D) shows that political regime scores moved slowly toward the more autocratic from 1970 to 1990 before reversing course toward the democratic direction. The scores then moved dramatically in the democratic direction from 0.9 in 1991 to 3.1 in 2004.

Figure 2 shows that each of the four factors contributed between $1.34 \%$ and $46.58 \%$ of the gain in life expectancy throughout the lag periods of $0-10$ years. Economy and literacy were major determinants that accounted for $26.75 \%-46.58 \%$ and $23.71 \%-38.08 \%$, respectively, of the gains in life expectancy. Nutrition contributed $2.79 \%-5.14 \%$ to life expectancy gains, while the political regime contributed $1.34 \%-9.11 \%$. Overall, the combined effects of these socioeconomic and political factors contributed $54.74 \%-98.16 \%$ of the gain in life expectancy throughout the lag periods of 0-10 years.

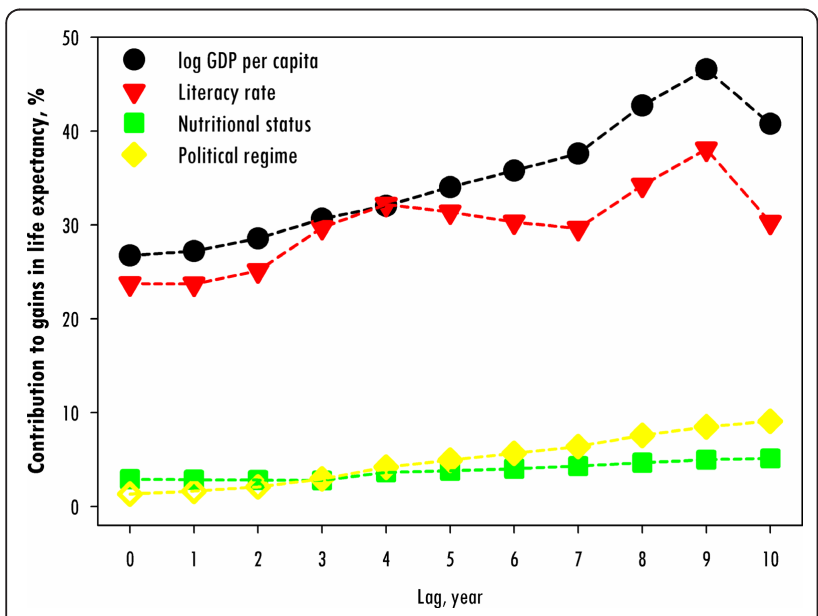

Figure 2 Contribution to gains in life expectancy for 119 countries on the basis of each variable from 1970 to 2004 estimated by linear mixed models, lagged from 0 to 10 years. Shaded symbols indicate statistically significant data in respect of the parameter estimation, while unshaded symbols are statistically non-significant.
Table 2 shows the modelling results of the four factors contributing to increases in life expectancy for 119 countries, with lag periods ranging from 0 to 10 years. All of the factors showed significantly positive effects on life expectancy throughout the lag periods of $0-10$ years, except for the political regime score. The political regime score showed a positive effect starting at the 3rd lagged year. When comparing the standardized coefficients of the lagged effect throughout 0-10 years, economy was the most important factor, followed by literacy, nutrition, and political regime. However, when we compared the ratios of these standardized coefficients, we found that the ratios decreased over time, especially the ratios that compared political regime to the other three factors. For example, in the 1st lagged year, the standardized coefficient of economy was 166 times higher than the standardized coefficient of political regime, but by the 10th lagged year, the ratio had decreased, and the coefficient for economy was only 27 times higher.

\section{Discussion}

This study contributes to the literature by quantifying the lagged effect of democracy and other socioeconomic factors on increased life expectancy over the 35 years of the study period. In our study, the four selected factorseconomy, literacy, undernourishment, and political regime-together contributed $55 \%-98 \%$ to the gains in life expectancy, given a lag period of up to 10 years. Improvements in a country's economy, education, and nutrition in 1 year exerted persistently positive effects on life expectancy during the subsequent 1-10 years, with the strongest effects seen in the earlier years. However, changes in political regime scores toward or away from democratic authority were more predictive of changes in life expectancy after a lag of $3+$ years. The findings regarding the three socioeconomic factors were generally in agreement with past research studies [22,40-42]. These findings point out the importance of investment in economy, education, and nutrition in developing countries [43,44], and especially in Africa, where approximately one-quarter of the population still suffers from undernourishment [36].

This study's modelling results show that gains in life expectancy can be attributed more directly to improvements in the national economy than to the other factors analyzed $[40,41]$. Research studies have shown that improvement in life expectancy appears to have a labor productivity effect and a positive effect on economic growth $[45,46]$. Our study findings further point out that improving economic status may also exert a positive effect on life expectancy for several years. This finding indicates a reciprocal relationship between economy and life expectancy. Improvement on either side may eventually benefit the other. 
Table 2 Contemporaneous and one- to 10-year lagged effects of determinants on life expectancy for 119 countries from 1970 to 2004 as estimated by linear mixed models

\begin{tabular}{|c|c|c|c|c|c|c|c|c|c|c|c|c|c|c|c|}
\hline \multirow[b]{2}{*}{ Models } & \multirow[b]{2}{*}{ N } & \multirow[b]{2}{*}{$n$} & \multicolumn{12}{|c|}{ Parameter estimates } & \\
\hline & & & $\beta_{0}$ & P Value & $\beta_{1}$ & $P$ Value & $\beta_{2}$ & $P$ Value & $\beta_{3}$ & $P$ Value & $\beta_{4}$ & $P$ Value & $\beta_{5}$ & P Value & \\
\hline Lag 0 & 119 & 1268 & 34.505 & $<0.001$ & 0.147 & $<0.001$ & 3.955 & $<0.001$ & 0.104 & $<0.001$ & 0.035 & $<0.001$ & 0.017 & 0.155 & 0.983 \\
\hline Lag 1 & 118 & 1228 & 35.470 & $<0.001$ & 0.142 & $<0.001$ & 3.891 & $<0.001$ & 0.101 & $<0.001$ & 0.034 & $<0.001$ & 0.020 & 0.107 & 0.982 \\
\hline Lag 2 & 116 & 1114 & 35.670 & $<0.001$ & 0.131 & $<0.001$ & 3.978 & $<0.001$ & 0.103 & $<0.001$ & 0.033 & $<0.001$ & 0.025 & 0.069 & 0.978 \\
\hline Lag 3 & 116 & 1001 & 34.888 & $<0.001$ & 0.105 & $<0.001$ & 4.107 & $<0.001$ & 0.119 & $<0.001$ & 0.033 & $<0.001$ & 0.034 & 0.028 & 0.972 \\
\hline Lag 4 & 116 & 889 & 33.674 & $<0.001$ & 0.086 & $<0.001$ & 4.218 & $<0.001$ & 0.129 & $<0.001$ & 0.045 & 001 & 0.048 & 005 & 0.963 \\
\hline Lag 5 & 116 & 889 & 34.378 & $<0.001$ & 0.078 & 0.003 & 4.285 & $<0.001$ & 0.121 & $<0.001$ & 0.044 & $<0.001$ & 0.056 & 0.002 & 0.964 \\
\hline Lag 6 & 116 & 889 & 35.280 & $<0.001$ & 0.072 & 0.007 & 4.298 & $<0.001$ & 0.114 & $<0.001$ & 0.043 & $<0.001$ & 0.063 & $<0.001$ & 0.965 \\
\hline Lag 7 & 116 & 889 & 36.162 & $<0.001$ & 0.064 & 0.017 & 4.292 & $<0.001$ & 0.107 & $<0.001$ & 0.043 & $<0.001$ & 0.071 & $<0.001$ & 0.966 \\
\hline Lag 8 & 116 & 793 & 35.153 & & 0.030 & 0.278 & 4.613 & $<0.001$ & 0.119 & $<0.001$ & 0.043 & $<0.001$ & 0.084 & $<0.001$ & 0.957 \\
\hline $\operatorname{Lag} 9$ & 116 & 697 & 34.049 & $<0.001$ & -0.005 & 0.861 & 4.915 & $<0.001$ & 0.132 & $<0.001$ & 0.045 & $<0.001$ & 0.098 & $<0.001$ & 0.944 \\
\hline Lag 10 & 113 & 582 & 31.609 & $<0.001$ & -0.056 & 0.092 & 5.503 & $<0.001$ & 0.140 & $<0.001$ & 0.058 & $<0.001$ & 0.143 & $<0.001$ & 0.920 \\
\hline
\end{tabular}

$\mathrm{N}=$ number of countries; $n=$ number of observations; $\rho=$ estimate of the first order autocorrelation coefficient

Democracy offers health benefits, as has been seen in Soviet and Eastern European countries that experienced a transition from autocracy to democracy in the 1990s $[10,47]$. Our models found significant lagged effects of political regime on life expectancy, and this result is generally in line with previous findings. People living in democracies may be empowered with responsibility and awareness of their own health which could result in better health outcomes. However, the findings from the current study showed that the effect of increased democracy could take up to 3 years to manifest. What caught our attention was the magnitude of the increased influence of political regime over time, especially when compared to the influence of the three socioeconomic factors. Political regime had the least influence on increased life expectancy to begin with. Effects did not become significant until year 3 , but then they continued to increase. Thus the impact of democracy on life expectancy continued to increase over time, while the impact of the three socioeconomic factors started strong but decreased over time. In each subsequent lagged year, the ratio of the standardized coefficients of the three socioeconomic factors to the standardized coefficient of political regime continued to decrease. This indicates that the relative importance of political regime to life expectancy increased over time when compared to the other factors investigated in this study. If this trend were found to continue, political regime might within two decades become a determinant as important as economy, literacy, and nutrition to increased life expectancy.

To our knowledge, this is the first study to address the longitudinal effects of political regime on life expectancy among LDCs while adjusting for time and regional correlations. Previous studies of the effects of political regime and socioeconomic factors on life expectancy were based on developed countries or on a mix of developed and developing countries $[7,8,10,42]$. Studies with a specific focus on developing countries have examined only single time points of data and have not considered the effects of both political regime and socioeconomic status in the analysis [7,42]. The results of our cross-country longitudinal analysis indicated that the development of public policy designed to meet social needs on improving the economy, education, and nutrition should make an important and positive contribution to population health in LDCs $[7,42,44]$. Most important, our findings point out that the benefits of democracy, unlike other determinants, are likely to continue to grow over time. If the identified trend is found to continue, democracy could become the most important health determinant to study in the future.

\section{Limitations}

We extracted global data from publicly available databases to enhance data comparability with previous studies. However, the long-term data from these sources (particularly for the 1970s) are usually incomplete, and this may have affected the fitness of our linear mixed models. Having assumed that the pattern of missing data was missing at random, we applied the complete case analysis to our models. If the missing rate could be reduced, we could expect a better model fitness and parameter estimation. Another limitation of our data analysis is that we chose to render the factor scale in terms of percentage or rank constitutes. Using this scale, our models cannot identify the significant determinants of life expectancy among countries for variables with limited variation and values approaching the minima or maxima, which values were seen with both literacy and undernourishment. Population size is an important factor to be considered in evaluating 
population health. A weighted analysis may provide better estimation when using aggregated data from random samples of a population to make inferences at the individual level. As a weighted analysis at the country level is likely to bias results toward more populous countries, unweighted analysis has been recommended to avoid fallacy in an ecological study such as this one $[48,49]$. Therefore, we decided to report unweighted results as our main findings in this paper. We believe the effect of population size has been partially considered by selecting indicators representing country-level characteristics and have made inferences carefully at the country level only. Three of our five independent variables, including economy, literacy, and undernourishment, have been normalized by population for each country, while the other two variables, time and political regime, are country-level characteristics which should not be affected by population size. Hence, applying population-weighted analyses to our models will cause estimated parameters biased and unexplainable. We have actually performed WEIGHT function in the PROC MIXED procedure in our analysis, and found that these models became unstable with fluctuated (positive and negative directions) parameter estimates for the fixed effects. This indicated that normalized variables have returned to non-normalized after we weighted population-normalized variables by population size again. However, it should be noted that our findings must be cautiously interpreted within the constraints of an ecological study $[48,49]$. Another limitation is posed by the physical and socioeconomic determinants of population health that were not measured by our study due to the scarcity of available data. We may have overestimated the effects of significant factors in our models by not fully considering unmeasured factors such as hygiene/sanitation status, health care systems, industrialization, technological progress, natural and manmade disasters, global changes, and HIV/AIDS pandemics [47,50]. We largely assumed that our use of geographical regions would act as a proxy variable for these unmeasured variables.

In spite of these limitations, our study has several methodological strengths. Specifically, to our knowledge this study included the largest number of LDCs of any analysis to date. In addition, it included lag effects, used an estimation of random effects, and incorporated linear mixed models in the analysis. By applying time-lag effects, adjusting for random effects, and considering multiple factors in our analyses, we were able to capture 90.01\%-91.42\% of the variations in life expectancy seen in contemporaneous and lag models. Moreover, the random intercept in our model representing geographic heterogeneity aimed to control unstructured spatial correlations, and could result in a better parameter estimation of the studied variables. With these improvements, we were able to provide empirical evidence for how life expectancy has improved over the past few decades in 119 LDCs as a result of contemporaneous and lagged effects of economic growth, increases in literacy, nutritional improvements, and political democratization. We recommend that future campaigns to increase life expectancy adopt multifaceted approaches and consider the interplay among socioeconomic and political determinants.

\section{Conclusions}

Though the short-term impact of democracy on increasing life expectancy is relatively small when compared to that of socioeconomic factors such as economy and nutritional status, the long-term impact of democracy increases over time and should not be underestimated. Our findings suggest, for example, that in Africa-where 35 African countries $(78 \%)$ were still not categorized as democracies as of 2000-2004-any campaign to prolong life expectancies should include goals for political democratization in addition to economic development and nutritional improvements.

\section{Abbreviations \\ UN: United Nations; USCB: United States Census Bureau; GDP: Gross domestic product}

\section{Acknowledgements}

This work was supported by the National Science Council of Taiwan [grant numbers NSC 96-2314-B-002-003, NSC 97-2314-B-002-075-MY3]. We are sincerely grateful to Professor Chan Chee Khoon of the Health and Social Policy Research Cluster and the Women's Development Research Centre at Universiti Sains Malaysia and to Dr. Chu-Chih Chen of the Division of Biostatistics and Bioinformatics at National Health Research Institutes of Taiwan for their critical comments on this manuscript, and to Ms. Jennifer Hou for her careful proofreading

\section{Author details}

${ }^{1}$ Institute of Occupational Medicine and Industrial Hygiene, College of Public Health, National Taiwan University, Room 722, No. 17, Xuzhou Road, Taipei City 100, Taiwan. ${ }^{2}$ Department of Internal Medicine, Division of Health Behavior Research, School of Medicine, Washington University in St. Louis, 4444 Forest Park Avenue, Suite 6700, St. Louis 63108, USA. ${ }^{3}$ Global Health Center, College of Public Health, National Taiwan University, No. 17, Xuzhou Road, Taipei City 100, Taiwan.

\section{Authors' contributions}

R-TL, Y-MC, and C-CC formulated the idea and led the study design, analysis, interpretation of the data, preparation of the manuscript, and critical revision of the manuscript for the core intellectual content. L-CC contributed to the statistical analysis and interpretation of the data. All authors contributed to discussing the content and the writing of the manuscript.

\section{Competing interests}

The authors declare that they have no competing interests.

Received: 10 August 2011 Accepted: 27 January 2012

Published: 27 January 2012

\section{References}

1. Wilmoth JR: Demography of longevity: past, present, and future trends. Exp Gerontol 2000, 35(9-10):1111-1129. 
2. Vagero D: Health inequalities across the globe demand new global policies. Scand J Public Health 2007, 35(2):113-115.

3. Moser K, Shkolnikov V, Leon DA: World mortality 1950-2000: divergence replaces convergence from the late 1980s. Bull World Health Organ 2005 83(3):202-209.

4. United Nations (UN): World Population Prospects: The 2006 Revision. [http://www.un.org/esa/population/publications/wpp2006/wpp2006.htm].

5. Shen CE, Williamson JB: Child mortality, women's status, economic dependency, and state strength: a cross-national study of less developed countries. Soc Forces 1997, 76(2):667-694.

6. Mahfuz K: Determinants of life expectancy in developing countries. J Dev Areas 2008, 41(2):185-204.

7. Franco A, Alvarez-Dardet C, Ruiz MT: Effect of democracy on health: ecological study. BMJ 2004, 329(7480):1421-1423.

8. Navarro V, Muntaner C, Borrell C, Benach J, Quiroga A, Rodriguez-Sanz M, Verges N, Pasarin Ml: Politics and health outcomes. Lancet 2006, 368(9540):1033-1037.

9. Gerring J, Bond P, Barndt WT, Moreno C: Democracy and economic growth: a historical perspective. World Polit 2005, 57(3):323-364.

10. Lake DA, Baum MA: The invisible hand of democracy: political control and the provision of public services. Comp Polit Stud 2001, 34(6):587-621.

11. Flegg AT: Inequality of income, illiteracy and medical care as determinants of infant mortality in underdeveloped countries. Popul Stud 1982, 36(3):441-458.

12. Ruger JP, Kim HJ: Global health inequalities: an international comparison. J Epidemiol Community Health 2006, 60(11):928-936.

13. Cattaneo LB, Chapman AR: The process of empowerment: a model for use in research and practice. Am Psychol 2010, 65(7):646-659.

14. Perkins DD: Speaking truth to power: empowerment ideology as social intervention and policy. Am J Community Psychol 1995, 23(5):765-794.

15. Perkins DD, Zimmerman MA: Empowerment theory, research, and application. Am J Community Psychol 1995, 23(5):569-579.

16. Wallerstein N: Powerlessness, empowerment, and health: implications for health promotion programs. Am J Health Promot 1992, 6(3):197-205.

17. Ross M: Is democracy good for the poor? Am J Pol Sci 2006, 50(4):860-874.

18. Ncayiyana DJ: Is democracy good for people's health? A South African perspective. BMJ 2004, 329(7480):1425-1426.

19. McKee $M$, Nolte $E$ : Lessons from health during the transition from communism. BMJ 2004, 329(7480):1428-1429.

20. Cannon MJ, Warner L, Taddei JA, Kleinbaum DG: What can go wrong when you assume that correlated data are independent: an illustration from the evaluation of a childhood health intervention in Brazil. Stat Med 2001, 20(9-10):1461-1467.

21. Black RE, Allen LH, Bhutta ZA, Caulfield LE, de Onis M, Ezzati M, Mathers C, Rivera J: Maternal and child undernutrition: global and regional exposures and health consequences. Lancet 2008, 371(9608):243-260.

22. Barlow R, Vissandjee B: Determinants of national life expectancy. Rev Can Etudes Dev 1999, 20(1):9-29.

23. Marks DF: Literacy not intelligence moderates the relationships between economic development, income inequality and health. $\mathrm{Br} J$ Health Psychol 2007, 12(Pt 2):179-184.

24. Preston $\mathrm{SH}$ : The changing relation between mortality and level of economic development. Popul Stud 1975, 29:231-248.

25. Rao V: Diet, mortality and life expectancy: a cross national analysis. J Popul Econ 1988, 1(3):225-233.

26. Kinsella KG: Changes in life expectancy 1900-1990. Am J Clin Nutr 1992, 55(Suppl 6):1196S-1202S

27. Prentice AM, Gershwin ME, Schaible UE, Keusch GT, Victora CG, Gordon Jl: New challenges in studying nutrition-disease interactions in the developing world. J Clin Invest 2008, 118(4):1322-1329.

28. Marmot M: Achieving health equity: from root causes to fair outcomes. Lancet 2007, 370(9593):1153-1163.

29. Prinja S, Kumar R: Reducing health inequities in a generation: a dream or reality? Bull World Health Organ 2009, 87(2):84.

30. United States Census Bureau (USCB): Global Population Profile: 2002 International Population Reports WP/02 Washington, DC: U.S. Government Printing Office; 2004

31. United States Census Bureau (USCB): International data base. [http://www. census.gov/ipc/www/idb].
32. Marshall MG, Jaggers K, Gurr TR: Polity IV project: political regime characteristics and transitions, 1800-2006. [http://www.systemicpeace.org/ polity/polity4.htm]

33. Heston A, Summers R, Aten B: Penn World Table version 6.2. [http://pwt. econ.upenn.edu/php_site/pwt_index.php]

34. United Nations Development Programme (UNDP): Human development report.[http://hdr.undp.org/en/reports].

35. United Nations Organization for Education, Science and Culture (UNESCO) UNESCO Data Centre.[http://stats.uis.unesco.org].

36. Food and Agriculture Organization (FAO): Food security statistics. [http:// www.fao.org/corp/statistics].

37. Laird NM, Ware JH: Random-effects models for longitudinal data. Biometrics 1982, 38(4):963-974.

38. Verbeke G, Molenberghs $\mathrm{G}$ : Linear mixed models for longitudinal data New York: Springer; 2000.

39. Akaike $\mathrm{H}$ : A new look at the statistical model identification. IEEE Trans Automat Contr 1974, 19(6):716-723.

40. Sachs JD, Mellinger AD, Gallup JL: The geography of poverty and wealth. Sci Am 2001, 284(3):70-75.

41. Kakwani N: Performance in living standards: an international comparison J Dev Econ 1993, 41(2):307-336.

42. Schell CO, Reilly M, Rosling H, Peterson S, Ekstrom AM: Socioeconomic determinants of infant mortality: a worldwide study of 152 low-, middle, and high-income countries. Scand J Public Health 2007, 35(3):288-297.

43. Florentino RF, Pedro RA: Nutrition and socio-economic development in Southeast Asia. Proc Nutr Soc 1992, 51(1):93-104.

44. Schiff M, Valdes A: Poverty, food intake, and malnutrition: implications for food security in developing countries. Am J Agric Econ 1990, 72(5):1318-1322

45. Bloom DE, Canning D, Sevilla J: The effect of health on economic growth: a production function approach. World Dev 2004, 32(1):1-13.

46. Commission on Macroeconomics and Health $(\mathrm{CMH})$ : Macroeconomics and health: investing in health for economic development. Report of the $\mathrm{CMH}$. Geneva: World Health Organization (WHO); 2001.

47. McMichael AJ, McKee M, Shkolnikov V, Valkonen T: Mortality trends and setbacks: global convergence or divergence? Lancet 2004, 363(9415):1155-1159.

48. Frohlich N, Carriere KC, Potvin L, Black C: Assessing socioeconomic effects on different sized populations: to weight or not to weight? J Epidemiol Community Health 2001, 55(12):913-920.

49. Morgenstern H: Ecologic Studies in Epidemiology: Concepts, Principles, and Methods. Annu Rev Public Health 1995, 16(1):61-81.

50. McMichael AJ, Butler CD: Emerging health issues: the widening challenge for population health promotion. Health Promot Int 2006, 21(Suppl 1):15-24.

\section{Pre-publication history}

The pre-publication history for this paper can be accessed here: http://www.biomedcentral.com/1471-2458/12/85/prepub

doi:10.1186/1471-2458-12-85

Cite this article as: Lin et al:: Political and social determinants of life expectancy in less developed countries: a longitudinal study. BMC Public Health 2012 12:85.

\section{Submit your next manuscript to BioMed Central and take full advantage of:}

- Convenient online submission

- Thorough peer review

- No space constraints or color figure charges

- Immediate publication on acceptance

- Inclusion in PubMed, CAS, Scopus and Google Scholar

- Research which is freely available for redistribution

Submit your manuscript at www.biomedcentral com/submit
C Biomed Central 